\title{
The Formation of Highly-Cooperative Organizational Climate Considering Impacts of Organizational Commitment and Team Cohesion
}

\author{
Haihui Guo \\ Yunnan University of Finance \& Economics \\ Kunming, 650221 China \\ 171053221@qq.com
}

\begin{abstract}
In an organizational team, the climate of the cooperative organization is very important to team success. The organizational commitment is the basis for the establishment of the team. However, team cohesion and organizational commitment play a certain role in it. This study uses the innovative project teams of a listed companies as its research object, and discusses how organizational commitment and team cohesion affect the team's cooperative climate. The results show that organizational commitment and team cohesion have a positive impact on the formation of a highly-cooperative climate.
\end{abstract}

Keywords-organizational; commitment; team; cohesion; cooperative organizational climate

The strength of the organization lies in the joint effort. In some key areas and when major breakthroughs are to be made, the team's full cooperation is the key to success. Rycroft \& Kash believes that collaborative team organization climate must be established in the current organizational system, such as education and training programs, work team design and information technology and other policies, in order to effectively promote the willingness of employees and promote high cohesion. Col \& Pmith proposes that organizational commitment can influence the behavior of knowledge sharing among employees and thus promote the exchange and integration of knowledge.

\section{CONCEPTS AND DEFINITIONS}

\section{A. Organizational Commitments}

The concept organizational commitment has grown in popularity in the literature on industrial and organizational psychology [5]. Early studies on organizational commitment viewed the concept as a single dimension, based on an attitudinal perspective, embracing identification, involvement and loyalty [15]. Organizational commitment is "a state in which an employee identifies with a particular organization and its goals, and wishes to maintain membership in the organization". Organizational commitment is therefore, the degree in which an employee is willing to maintain membership due to interest and association with the organization's goals and values.
Organizational members, who are committed to an organization on an affective basis, continue working for the organization because they want to [14]. Members who are committed on an affective level stay with the organization because they view their personal employment relationship as congruent to the goals and values of the organization.

Meyer and Allen further state that "employees whose primary link to the organization is based on continuance commitment remain because they need to do so" [14]. This indicates the difference between continuance and affective commitment. The latter entails that individuals' stay in the organization because they want to. Continuance commitment can be regarded as an instrumental attachment to the organization, where the individual's association with the organization is based on an assessment of economic benefits gained. Organizational members develop commitment to an organization because of the positive extrinsic rewards obtained through the effort-bargain without identifying with the organizational goals and values.

Flynn believes that the organization is committed to the long-term development and continuous contribution of team members. Through continuous investment in the organization, it forms a good climate of cooperative organization [9]. Its characteristics include selective recruitment, development assessment, competitiveness and fairness. Sexual compensation, comprehensive training and developmental activities [18].

Based on the above studies, the organizational commitment emphasizes the interaction between the two parties and the longer-term exchange relationship. The organizational commitment has a positive impact on the company's performance. In addition, $\mathrm{Col} \&$ Pmith confirmed that human resource management practices based on organizational commitments will affect the knowledge sharing behavior of employees [7]. Therefore, this study will adopt the approach of questionnaire, which is divided into three aspects: motivation, training and development in three parts.

\section{B. Team Cohesion}

Team cohesiveness was first formed by McDougall who proposed "an intuition of group gregariousness" [13]. In 1950, Festinger defined team cohesion as a force to drive the team, 
and also as a force to suppress the leaving team, and this kind of power would make the members actively remain in the team. Carron believes that team cohesion is a dynamic process in which members of a group are closely integrated with each other and together accomplish the goals of the team. Forsyth believes that team cohesion refers to the sense of identity that members maintain in their relationship with each other in the team, the collective belief in common goals and values, and the collective willingness to help the team [10]. "Mission" refers to the purpose and goal of the team. Group cohesion is also considered to be a belief shared by team members [4].Forsyth and Wright \& Drewery pointed out that highly cohesive groups will exhibit high degree of cooperation and satisfaction among their members and have high commitment to their organizational goals [19]. Therefore, the level of cohesion is not only important for individual needs, but also more important for the survival and development of the organization. In general, cohesion does not occur naturally and must be generated by participating in various activities or tasks.

Carron, et al. thought that team cohesion can be divided into two categories: team integration and personal attraction to the team [4]. Team integration means that the individual team members are required to evaluate the entire team according to team tasks and interpersonal relationship activities; the attractiveness of individuals to enter the team refers to the degree to which individual members of the team are accepted after joining the team, and other members' interpersonal relationships. A feeling of. Individuals are further subdivided into human relationships and tasks. Interpersonal relationships are the development and maintenance of social relationships in teams.

Based on the aforementioned literature, this study defines team cohesion as "the degree to which team members attract each other and are willing to stay within the team, and is willing to contribute to the benefit of the group and complete the goals set by the group. Cohesion of the community is an attractive member of the community activities. And the power of mutual attraction among community partners is also the psychological feeling of members who want to integrate into the community and work together with other members. Therefore, this study summarizes the concept of Carron et al. and revises the model of team cohesion as a cohesion model of the community. It is composed of four levels: "community mission cooperation", "community interpersonal affinity", "community task adaptation" and "association of community contacts".

\section{Cooperative Organizational Climate}

Organizational Climate was first proposed by the scholar Kurt Lewin in Field Theory in 1930. He pointed out that to understand human behavior, it is necessary to consider the entire situation in which the behavior takes place. This whole situation is personal and environment. Climate is the result of the interaction between individuals and organizations and forms perception. However, since the evolution of the organization's climate so far, scholars have often adopted a "strategic" perspective to explore the organizational climate. Their viewpoints have changed from a general-purpose, general-purpose perception of the organization's climate to cognition of climate-linked, specific-to-specific strategies. , Strategic cognition, such as innovation organization climate, service organization climate, cooperative organization climate, etc. Coupled with the use of self-management teams since the 1990s, the importance of cooperation and teamwork for organizational effectiveness has been highlighted [6]. This study uses the climate of cooperatives.

Campbell \& Pritchard defines cooperative climate as the process by which an individual competes with other members in an organization or accomplishes something together [2]. The collaborative organization climate was defined as an organization that often emulates the results of individual efforts to the group rather than personal results. When employees have common goals, they tend to cooperate with each other to achieve those goals. Tom \& Steven believes that cooperation is because individuals want to create and maintain a favorable identity, and the material resources that the members of the organization receive from the team and may face a sanctions crisis will affect the degree of team member cooperation [13]. Aukje \& Lsabel further elaborated on organizations with cooperative climate, whose members would spontaneously support and support each other, and had a high degree of cohesion and team spirit, and were satisfied with the team they belonged to [1].

Briefly, this research defines the collaborative organization climate in which employees within the organization perceive that they want to be spontaneous and cooperate with other organization members to achieve organizational goals. In this study, each company adds up individual perception scores and uses the added average to represent the extent to which the company collectively perceives climate. Therefore, the collaborative climate of this study is a higher level concept. The questionnaire used Koy \& DeCotiis's question about cohesive facets in the organizational climate as the subject of this study [11]. It mainly asked the company's colleagues how to get along with each other, whether to get along well, help each other, and care for each other.

\section{RATIONALE}

Recruitment and recruitment adopted by organizational commitments emphasizes the understanding between the applicant and the organization, and the ability to integrate and build relationships [12]. Education and training also emphasize the ability to build interpersonal relationships and develop skills. "Interpersonal relationships" is an important factor in the development and maintenance of social relationships in team cohesion. The Tom \& Steven study found that the level of resources that team members receive from organizational commitments will determine the extent to which they work with other members. In summary, we can find that organizational commitment and team cohesion have positive effects [17]. This study deduces hypothesis H1:

H1: Organizational commitment has a positive effect on team cohesion.

The organizational climate was defined as a formal and informal understanding of the organization's policies, practices, and procedures. This is similar to the meaning of organizational commitments, and organizations may effectively 
influence the interaction of employees through different organizational commitments [12]. David \& Cheri also believes that human resource management practices will affect employees' perception of the organization's climate [8]. The human resource management practice based on "commitment" emphasizes that the integration of the interests of employees and employers will create a mutually reinforcing relationship. Therefore, employees will perceive that they want to cooperate with employers to form a cooperative organizational climate, and thus improve employees' Contribution of the organization. In summary, we learned that there is a positive relationship between organizational commitment and the climate of cooperative organizations. Therefore, this study deduces hypothesis $\mathrm{H} 2$ :

H2: Commitment-based human resource management practices have a positive impact on the climate of cooperative organizations.

$\mathrm{Xu}$ Shijun pointed out that the organizational climate is not only related to the general satisfaction of work, but also related to many facets of job satisfaction, such as interpersonal relationships and team cohesion [20]. Organizations that have a high level of group cohesion, in order to maintain strong ties with each other, will resist any act that threatens this ambiguity. A high degree of cohesion can help members to more quickly join each other's cooperative relations and form a cooperative climate where members are willing to help and support each other and are highly cohesive and satisfied with the team they belong to. In summary, we find that team cohesion has a positive relationship with the climate of cooperative organizations. Therefore, this study deduces hypothesis H3:

H3: Team cohesion has a positive impact on the climate of the cooperative organization.

\section{MeAsurement \& SAMPle}

The Organizational Commitment Scale refers to the scale proposed by Christopher \& Ken and is divided into three major dimensions [5]. There are four questions for the selection of the facets; four questions for the motivational facets; eight questions for the training and development facets, of up to 16 questions. The Cohesion Scale for Team Coherence is a survey of the interactions among colleagues in the work unit of respondents in a proper scale, a total of ten questions. The Cooperative Climate Measurement Scale Reference Koy \& DeCotiis conducted a survey on the climate of the organization and used the team's cohesiveness as the basis of the questionnaire [11].

This research object is a sample of technology companies that are publicly traded on the stock exchange, and lists companies that meet the research conditions and are willing to cooperate with the implementation of the questionnaire survey. A total of 18 high-tech companies participated in the study. The questionnaire was sent by paper and e-mail in March 2016. A total of 600 questionnaires were issued. Each company issued 10 to 40 copies. Recycling was completed in June. A total of 394 questionnaires were returned with a $65 \%$ recovery rate. After deducting invalid questionnaires that were not answered correctly, a total of 326 valid questionnaires were returned from 15 companies.

\section{RESULTS}

With application of SPSS analysis, dataset of organizational commitment, team coherence and cooperative organizational climate got the Cronbach's Alpha as 0.702, 0.763 and 0.817 . The dataset of measurement passed the reliability test and validity test.

There was a positive correlation between organizational commitment and team cohesion $(\mathrm{r}=0.175, \mathrm{p}<0.01)$; a positive relationship between organizational commitment and climate of cooperating organizations $(\mathrm{r}=0.434, \mathrm{p}<0.01)$; a positive correlation between team cohesion and climate of cooperating organizations $(r=0.312 ; \mathrm{p}<0.01)$, and all of the above have reached significant levels.

First, we use the ICC as the reliability index of this study. It is divided into two parts. ICC (1) is the variation ratio of the total variation in the evaluation variable, which is explained by the team members; ICC (2) is the stability of the average number of the assessment team level. The value of ICC (1) usually falls between 0 and 0.5 . The ICC (1) in this study is in the range of standard value 0 to 0.5 except that the cooperative climate $(-0.008372)$ is negative. However, since the value is already close to zero, the reliability among the scorers is still acceptable. This also means that the team members of the cooperative climate explained the percentage is poor. In addition, ICC (2) is positive, indicating that the variation between the groups is greater than the within-group variation.

According to the statistical results, the R-square of the overall regression model was $5.1 \%$, the explanatory variance was $3.7 \%$, and the overall regression model had significant explanatory power $(\mathrm{F}=3.705, \mathrm{p}=0.001)$. The significant level indicates that organizational commitment affects team cohesion $(\beta=0.079)$. Therefore, this statistical result supports hypothesis 1: Organizational commitment has a positive impact on team cohesion.

The overall regression model has an R-square of $20.1 \%$, an increased interpretation of variance of $18.9 \%$, and an overall regression model with significant explanatory power $(\mathrm{F}=17.394, \mathrm{p}=0.000)$ at a significant level, indicating organizational commitment. It will affect the climate of cooperative organizations $(\beta=0.248)$, so this statistical result supports hypothesis 2: The organizational commitment has a positive impact on the climate of cooperative organizations.

The R-square of the overall regression model was $9.7 \%$, the explanatory variance was $8.4 \%$, and the overall regression model had significant explanatory power $(\mathrm{F}=7.425, \mathrm{p}=0.000)$, which was significant, indicating team cohesion. It will affect the climate of cooperative organizations $(\beta=0.409)$, so this statistical result supports the hypothesis 3: Team cohesion has a positive influence on the climate of cooperative organizations.

\section{CONCLUSIONS \& RECOMMENDATIONS}

\section{A. Conclusions}

This study found that committed human resource management practices have a significant relationship with team cohesion. It confirmed that team cohesion can be influenced by the measures of HR management practice. Furthermore, the 
selection used in the commitment-based human resource management practice emphasizes the tacit understanding between the applicant and the organization, social integration, and the ability to establish interpersonal relationships; close to the team members. The interaction will give its members ample opportunities to communicate with each other, and if the organization can provide team-based rewards, it will contribute to the team's momentum and promote the knowledge sharing behavior of employees; If training and development emphasize the ability to build interpersonal relationships and develop skills, the "personal relationship" is an important factor in the development and maintenance of social relationships in team cohesion.

From the literature data, it is found that human resource management practices will affect employees' perceptions of organizational climate, and that the team members' resources obtained from human resource management practices will also determine how he collaborates with other members. This study confirms that the commitment of human resources practices will affect the climate of cooperative organizations. It may be because committed human resource management practices will combine the interests of employees and employers to create a mutually reinforcing relationship. Therefore, employees will feel that they want to cooperate with employers and form a collaborative organization climate.

As the concepts of team cohesion and cooperative climate are similar, but team cohesion has a common sense of identity for two or more individuals, must achieve common goals, share a common destiny, and exhibit a structured interactive model and communication type. Organizational climate refers to the overall perception of the team, so at the level of team cohesion to influence the organization's cooperative organization climate.

In addition, the degree of cooperation among team members is mainly affected by the degree of integration of members and teams, and a highly cohesive team can assist members to more quickly join each other's cooperative relationships and form a cooperative climate. The empirical analysis shows that if an organization wants to foster a cooperative organizational climate, it can begin by promoting team cohesion.

\section{B. Recommendations}

Because the climate of cooperative organization is the perception of employees, it is necessary to combine the practical practices of organizational commitment-type human resources management in order to truly promote the cohesion and close cooperation of employees and promote innovation behavior. Due to the characteristics of the operation of hightech industries, it is often necessary to achieve organizational goals through teamwork or cross-departmental cooperation. Therefore, creating a cooperative climate is very important because when members of the organization "feel" the common goals of the organization, and the common goals of the organization are achieved through the mutual knowledgesharing behavior. The most important factor affecting the team's cohesion is the interpersonal attraction between members.

\section{ACKNOWLEDGMENT}

The author would like to thank the two anonymous reviewers for their constructive feedback throughout the review process. The author is bound to the accountabilities.

\section{REFERENCES}

[1] N. Aukje, \& G. Isabel, Social Comparison at Work as Related to Cooperative Social Climate and to Individual Differences in Social Comparison Orientation. International Association for Applied Psychology, 54(1):61-80, 2005.

[2] J.P. Campbell, \& R.D. Pritchard, Motivation Theory in Industrial and Organizational Psychology. In M. D. Dunnette (Ed.). Handbook of Industrial and Organizational Psychology. Chicago: Rand Mcnally, 1976.

[3] A.V. Carron, Cohesiveness in sports groups: Interpretations and considerations. Journal of Sport Psychology, 4, 123-138, 1982

[4] A.V. Carron, \& W.N. Widmeyer, \& L.R. Brawley, The development of an instrument to assess cohesion in sport team: The Group Environment Questionnaire. Journal of Sport Psychology, 7, 244-266, 1985.

[5] J.C. Christopher \& G.S. Ken. Knowledge Exchange and Combination: The Role of Human Resource Practices in the Performance of HighTechnology Firms. Academy of Management Journal, 49(3):544-560, 2006

[6] S.G. Cohen, G.E. Ledford, and G.M. Spreitzer, A predictive model of self-managing work team effectiveness, Human Relations, 49, pp. 643 676, 1996.

[7] Col \& Pmith. Human resource practices in the performance of high technology firms. India Academy of Management Journal, 42(1): 121,2006

[8] David, Cheri, HRM-firm normative management: The role of the high performed organizational system. Academy of Management Review, 109(1):1103-1123, 2014.

[9] J. Flynn, J. Francis Identity Organizations and Forms of Social Exchange in Organization, Academy of Management Review, 30, 4 737-750, 2005

[10] D.R. Forsyth, An Introduction to Group Dynamics, California: Brooks/Cole Publishing Company, 1983.

[11] D.J. Koy, \& T.A. DeCotiis, Inductive Measures of Psychological Climate. Human Relations. 44(3): 265-285, 1991.

[12] M.A. Huselid, the Impact of Human Resource Management Practices on Turnover, Productivity, and Corporate Financial Performance. 38(3):635-972, 1995.

[13] W. McDougall, Introduction to Social Psychology, John W. Luce and Company, New York, 1908

[14] Meyer, John \& Allen, Natalie. A Three-Component Model Conceptualization of Organizational Commitment. Human Resource Management Review. 1(1): 61-89,1991.

[15] L.W. Porter, R.M. Steers, R.T. Mowday, \& P.V. Boulian, Psychiatric Technicians. Journal of Applied Psychology, 59, 603-609, 1974.

[16] R.W. Rycroft, \& D. E. Kash. Path dependence in the innovation of complex technologies. Technology Analysis and strategic Management, 14(1), pp.21-35, 2002

[17] R. Tom ,Tyler \& L. Steven, Blader. The Group Engagement Model: Procedural Justice, Social Identity, and Cooperative Behavior. Personality and Social Psychology Review, Vol. 7, No. 4: 349-361, 2013

[18] E.M. Whitener, Do "high commitment" human resource practices affect employee commitment? A cross-level analysis using hierarchical linear modeling. Journal of Management, 27: 515-535, 2001

[19] N.S. Wright, \& G.P. Drewery, Forming cohesion in cultura heterogeneous teams: Differences in Japanese, Pacific Islander, and Anglo experiences. Cross-Cultural Management, 13, 43-53, 2006.

[20] Xu Shijun. Work in a Highly-Cooperative Social Climate Considering Individual Differences. Association for Applied Psychology, 254(1):92101, 2017. 